\title{
Parasitic Fauna of East European Hedgehog (Erinaceus Concolor) and Their Pathological Aspects in Iran
}

\author{
Ahmad Nematollahi ${ }^{1, *}$,Javad Ashrafi Helan ${ }^{1}$, Habib Golezardy ${ }^{2}$, Neda Zaboli $^{1}$, \\ Maryam Nouruzi ${ }^{1}$, Mehdi Azari ${ }^{1}$ \\ ${ }^{1}$ Department of Pathobiology, Faculty of Veterinary Medicine, University of Tabriz, Tabriz,Iran, Zip code: 5166616471 \\ ${ }^{2}$ Veterinarian, Lavasan Specialised Veterinary Polyclinic.1139Shorkab,Tehran,Iran,Zip code:3341635895 \\ *Corresponding Author: anemat@tabrizu.ac.ir
}

Copyright (C) 2014 Horizon Research Publishing All rights reserved.

\begin{abstract}
The first objective of the present study was to determine and quantify the diversity of ecto- and endo-parasites of hedgehogs as well as their pathologic lesions in Tabriz, Iran. A total of 42 hedgehogs were collected and examined. The hedgehogs harbored the adults of two ixodidae tick species belonging to two genera, namely Hyalomma excavatum and Rhipicephalus turanicus as well as two flea species of two genera, namely Ctenocephalides canis and Leptopsylla segnis. At necropsy, 173 helminthes were recovered from the internal organs. Phyasaloptera clausa (36.84\%), Mullerius capillaries $(25.18 \%)$ and Hymenolepis diminuta (3\%) were recognized in this survey. Microscopically, severe parasitic bronchitis and bronchiolitis, chronic interstitial pneumonia, hyperkeratosis, acanthosis, furunculosis, and chronic fibrosing gastritis were observed. The results of this study represent that hedgehogs are suitable hosts for the above mentioned parasites. Their pathological tissue damages were assessed.
\end{abstract}

Keywords Flea, Iran, Hedgehog, Pathology, Tick

\section{Introduction}

Hedgehogs, as nocturnal and spiny-coated omnivorous mammals with distinctive features, fall in the subfamily Erinaceinae of the order Erinaceomorpha. They prefer deciduous woodlands, scrub and opened grasslands as habitats (39). These mammals were historically classified into five genera and have currently distributed through parts of Europe, Asia, Africa and New Zealand and subspecies due to close genetic ties. Iran contains a taxonomically assortment of four species of hedgehogs, namely East European hedgehog (Erinacea concolor), Desert hedgehog (Hemiechinus oethiopicus), Long-eared hedgehog (Hemiechinus auritus) and Brandt's hedgehog (Hemiechinus hymelas) $[8,32,38]$. Hedgehogs have recently grown in popularity as exotic pets in the Iranian society. Generally hedgehogs with their capacity for rapid and sustained population growth may serve as reservoirs for a wide variety of pathogens, some of which may possess zoonotic characters $[9,16,29,32]$, therefore their potential risk of transferring them to humans has been discussed by various authors [14].

Globally there has been limited research conducted on parasite fauna of wild and domesticated hedgehogs $[4,6,9,14,17,18,25,33,37]$, however, comparatively fewer studies have been performed throughout Iran [12,20,21,37].

Despite the wide distribution of hedgehogs in Iran, there is not enough survey performed on endo and ectoparasites of this mammal in our country. The aims of this study were to determine the parasitic fauna and assess its pathologic importance in East European hedgehogs (Erinacea concolor) in Tabriz, North West of Iran.

\section{Materials and Methods}

\subsection{Survey Localities and Period}

This survey was carried out at the nature reserves in the suburb of Tabriz city $\left(38^{\circ} 04^{\prime} \mathrm{N}\right.$ and $46^{\circ} 18^{\prime} \mathrm{E}$; Alt. $\left.1351.4 \mathrm{~m}\right)$, located in North West of Iran from January to June 2012. The climate in the study area is known as temperate with relatively hot and dry summers and cold winters.

\subsection{Hedgehogs-trap Sampling}

At all localities a census line of 15 Sherman live traps spaced 10 meters apart were set. Traps were baited with a mixture of fruit and earthworms. Each trap line was set for two consecutive nights in a week for a period of six months, which resulted in 30 trapping nights per line per trapping session. Trapping times were selected for nocturnal hedgehogs since traps were closed during the day to avoid accommodation of undesired small mammals. The hedgehog trapped in the census line were placed in labeled bags and transported to the Section of Parasitology, at The Department of Pathobiology, Faculty of Veterinary 
Medicine, University of Tabriz for laboratory analyses. The hedgehogs were identified using the features proposed in the literatures [8].

\subsection{Ethical Considerations}

Permission was initially obtained from the Animal Use and Care Committee at the Faculty of Veterinary Medicine, University of Tabriz, Iran to collect hedgehogs and perform procedures for parasite recovery and pathological studies.

\subsection{Ecto- and Endo-parasite Recovery}

In the laboratory, the live hedgehogs were euthanized by a rapid intraperitoneal injection of $1 \mathrm{ml}$ of non-sterile Eutha-naze (Bayer, Animal Health Division, Germany). The body surface of each hedgehog was carefully searched for ectoparasites. The collected arthropods were preserved in $70 \%$ ethanol in internally labeled bottles. Using a stereoscopic microscope, they were then identified to species level according to the identification keys as well as by comparison with voucher specimens [34].

At necropsy, the abdominal and thoracic cavities were opened. The stomach, liver, lungs and intestines were separately dissected. After recording of macroscopic changes, their contents were gradually poured into a steel mesh sieve, with $150 \mu \mathrm{m}$ apertures and washed with a strong jet of water. The contents of the sieve were transferred to a container and from there, bit by bit into a square Perspex tray and examined under a stereoscopic microscope in order to collect helminths that had been dislodged. All collected helminths were finally identified making use of published descriptions and illustrations [30].

\subsection{Pathology}

The tissue samples were collected, fixed in $10 \%$ formalin, and routinely processed. Paraffin-embedded blocks were made and tissue sections, 5-6 microns in thickness, were cut by a microtome .The tissue samples were eventually stained with hematoxylin and eosin (H\&E).

\section{Results}

The cumulative average trap success attained was 42 individuals $(42 / 720=5.83 \%)$ identified as East European hedgehogs (Erinacea concolor). A total of 173 helminthes, including 165 nematodes and 8 cestodes were recovered from the internal organs (Table 1). The most prevalent helminthes species was Phyasaloptera clausa (36.84\%), followed by Mullerius capillaries (25.18\%) and Hymenolepis diminuta (3\%).

The hedgehogs harbored 40 ixodid ticks belonging to two genera and two species, namely Hyalomma excavatum (9.77\%) and Rhipicephalus turanicus (5.26\%) (Table 2), as well as 53 fleas of two genera and two species, namely was
Leptopsylla segnis $(18.42 \%)$ and Ctenocephalides canis $(1.5 \%)$ (Table 3). No immature stages of ticks were recovered. In general, 35 hedgehogs were found to be infected with one or more parasite species, and the overall infestation prevalence was $83.3 \%$.

Table 1. Species, location and prevalence of helminths recovered from 42 Iranian hedgehogs in the suburb of Tabriz, Iran

\begin{tabular}{|c|c|c|}
\hline Species & Location & Prevalence (\%) \\
\hline Hymenolepis diminuta & Small intestine & $8(3.00)$ \\
\hline Mullerius capillaris & Lungs & $67(25.18)$ \\
\hline Physaloptera clausa & Stomach & $98(36.84)$ \\
\hline
\end{tabular}

Table 2. Species and number of ticks collected from 42 Iranian hedgehogs in the suburb of Tabriz, Iran

\begin{tabular}{|c|c|c|c|c|c|}
\hline \multirow{2}{*}{ Tick species } & \multicolumn{2}{|c|}{ Gender and life stage of collected ticks } & $\begin{array}{c}\text { Total } \\
\text { number } \\
\text { of ticks }\end{array}$ \\
\cline { 2 - 5 } & Larvae & Nymphs & Males & Females & 26 \\
\hline $\begin{array}{c}\text { Hyalomma } \\
\text { excavatum }\end{array}$ & 0 & 0 & 23 & 3 & 14 \\
\hline $\begin{array}{c}\text { Rhipicephalus } \\
\text { turanicus }\end{array}$ & 0 & 0 & 9 & 5 & \\
\hline
\end{tabular}

Table 3. Species and number of fleas collected from 42 Iranian hedgehogs in the suburb of Tabriz, Iran

\begin{tabular}{|c|c|c|c|}
\hline \multirow{2}{*}{ Flea species } & \multicolumn{2}{|c|}{ Gender of collected fleas } & \multirow{2}{*}{$\begin{array}{c}\text { Total number } \\
\text { of fleas }\end{array}$} \\
\cline { 2 - 3 } & Males & Females & 4 \\
\hline $\begin{array}{c}\text { Ctenocephalides } \\
\text { canis }\end{array}$ & 1 & 3 & 49 \\
\hline Leptopsylla segnis & 38 & 11 & 4 \\
\hline
\end{tabular}

Macroscopically, thickness, crusting, hyperkeratosis, lichenification, papule formation, seborrhea and alopecia especially on spine-free region were observed. Lungs were congestive with numerous focal consolidations distributed throughout of lobules parenchyma and underpleura. Mineralization in some consolidates were noticed. Trachea and airways were congestive and a lot of white thready worms were present on the epithelia. In stomach, nematodes were often located in the first half of the mucosa. Occasionally, the head of worms deeply buried in the wall and were dislodged with force. In these cases, stomach contents were brownish. There were no parasites in the liver and biliary ducts.

Microscopically, severe hyperkeratosis, acanthosis with formation of long and rete ridges was present in skin. In some areas, hydropic degeneration of squamous cells, vesicles and pustules formation and parakeratosis was noticed. Also, sebaceous gland hyperplasia, folliculitis, perifolliculitis and furunculosis were observed (fig1).

In lung, heavy parasitic infestations, suppurative bronchitis and bronchiolitis, hyperplasia and stratified squamous metaplasia and in some areas, focal erosion of airways epithelia was present. Also, chronic interstitial pneumonia (chronic atypical pneumonitis) and scattered alveolar emphysema were noticed (fig 2, 3 and 4). Atherosclerosis was present in lung vessels. Chronic gastritis with atrophy of glands, periglandular and 
interglandular fibrosing and trace bleeding around of parasites deeply buried in the mucosa were observed. Cross sections of the nematodes were found within glands and under mucosal layer. Congestion and mild catarrhal enteritis were observed.

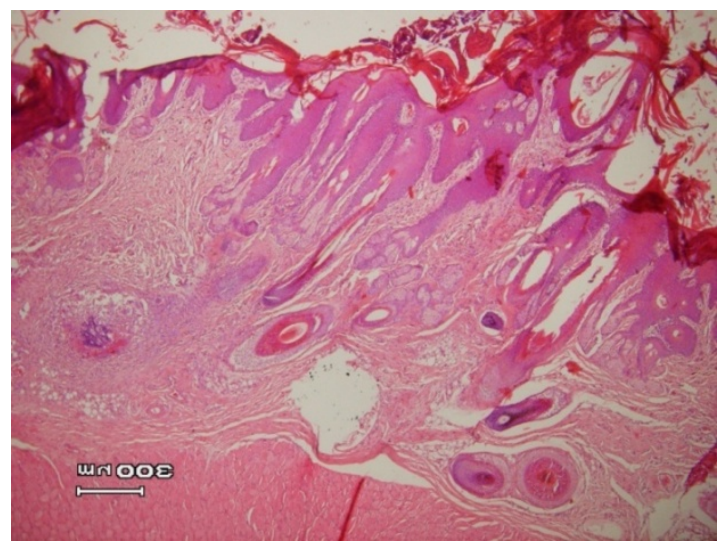

Figure 1. A microscopic section of skin, East European hedgehog: hyperkeratosis and acanthosis with formation of long rete ridges are present. Also, focal dermatitis (a furunculosis) is observed at middle part of the left side $(\mathrm{H} \& \mathrm{E}, \times 40)$

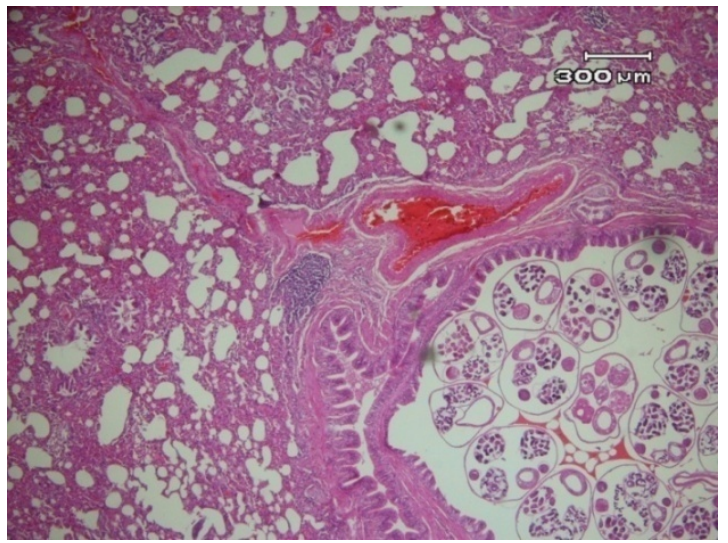

Figure 2. Microscopic view of lung, East European hedgehog: heavy parasitic infestation, severe parasitic bronchitis, chronic interstitial pneumonia (chronic atypical pneumonitis) and scattered alveolar emphysema are noticed $(\mathrm{H} \& \mathrm{E}, \times 40)$

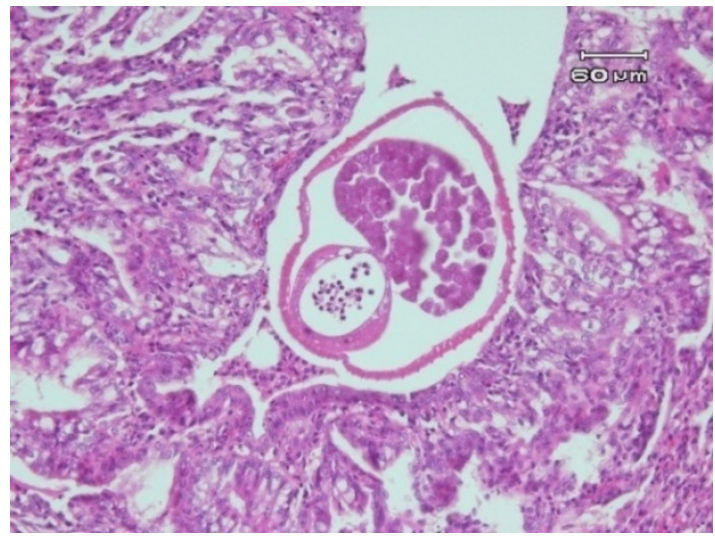

Figure 3. A histopathological section of bronchiole, East European hedgehog: section of the nematode in a bronchiole, chronic bronchiolitis with hyperplasia of epithelium are observed $(\mathrm{H} \& \mathrm{E}, \times 200)$

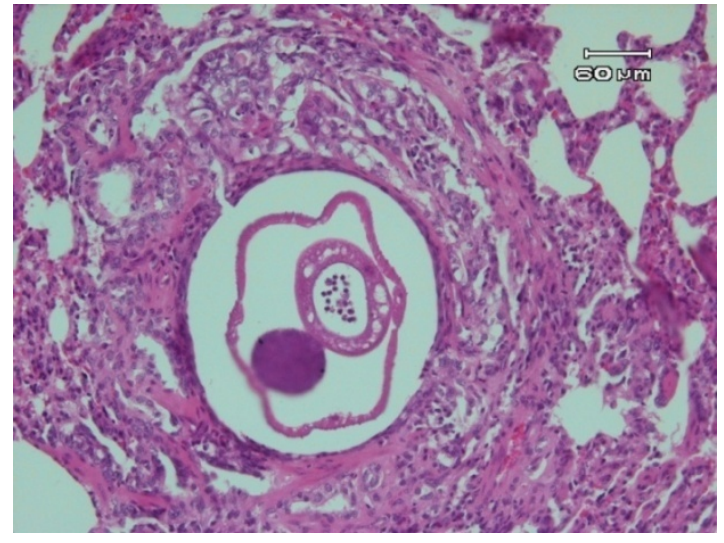

Figure 4. Microscopic view of lung, East European hedgehog: section of parasite (Mullerius capillaris) in a secondary bronchiole, severe hyperplasia of smooth muscles and stratified squamous metaplasia of the epithelium are present $(H \& E, \times 200)$

\section{Discussion}

There is a lack of knowledge of parasites infecting and/or infesting hedgehogs in various localities in Iran. Geographical distribution of parasites in our country may have different impacts on species composition of parasites in hedgehogs. Therefore, availability of this host in a region can result in completion of the life cycles of its preferred parasites.

In Iran, most of the previously published surveys focused on the identification of helminthes infecting hedgehogs. Helminths such as Physaloptera clausa [12] and Nephridiacanthus (oligacanthorhynchidae) [26] and Crenosoma striatum [21] were commonly recovered from hedgehogs at necropsy. Our results are consistence with the results of other authors in Iran [20,21,28].

Previous researchers reported lungworms Crenosoma striatum [6,13,17] and Capillaria aerophilia [4,15,17] associated with hedgehogs around the world, however, little study has been done on the infection rate of Crenosoma striatum in Iran [7,21]. The prevalence of Mullerius capillaries in small ruminants in the suburb of Tabriz city was evaluated by Golezardy (1999). In various surveys reported the infection of hedgehogs with this nematode was evident $[2,22]$. The lungworms require intermediate hosts such as slugs and snails [30], to complete their lifecycles. Those consist a high portion of hedgehog's daily diet [6,29,36]. Majeed et al. (1989) showed that infection rate with lungworms is proportional to the age of hedgehogs. However, no comparison was made in our study since age of hedgehogs was not considered.

Prevalence of infection with Mullerius capillaris was $25.18 \%$ of recovered worms and pathologic lesions were relatively severe. It seems this is related to seasons (winter and spring) in which the study was performed. It has been established that under stressful condition, such as lack of food or of an appropriate environment, bad weather condition, or diseases, the labile host-parasite relationship 
becomes imbalanced and infection may develop. Severe infection caused by parasites is more likely in juveniles or during hibernation. Coarse breathing sounds, coughing and wasting are typical signs in juvenile animals. Capillaria aerophila infect respiratory tract of hedgehogs feeding on worms that are storing the eggs [13]. Naem et al. 2006 reported severe bronchopneumonia due to heavy infestation of hedgehog lungs with Crenosoma striatum. Mild pneumonia, emphysema, bronchiolar thickening and extensive hemorrhages and granulomas due to eggs and larvae were previously reported in Metastrongylus elongatus infection in hedgehogs [24]. In our study, main pathologic changes of lungs were chronic bronchitis and bronchiolitis. Although, chronic atypical pneumonitis was present but there were no worms, larvae or the eggs within the alveoli.

In this study, the most prevalent helminthes species was Phyasaloptera clausa (36.84\% of recovered worms), and which caused chronic fibrosing gastritis. The pathologic lesions were similar to those previously reported by Goldberg and Bursey (1989) from naturally infected sagebrush lizards with Phyasaloptera retusa; Botella and Esteban (1995) described stomach lesion caused by Phyasaloptera brevivaginata in bats from Spain and Naem et al. (2006) assessed gastric lesions of cats due to Phyasaloptera praeputialis. . It seems that acute lesions of stomach such as hyperemia, eosinophilic gastritis, fibrinous degeneration and mucosal ulceration reported by Hoseini et al. (2012), are due to mild infestation and absence of the parasites within gastric mucosa, does not rule out exactly Phyasaloptera clausa infection.

The geographic distributions of many ixodid ticks occurring in Iran have already been determined and some of these distributions have been illustrated $[1,19,20,27,28]$. The tick species recovered from the hedgehogs in the study sites are species associated with temperate conditions. This applies to both Hyalomma excavatum and Rhipicephalus turanicus $[20,26]$. The similarity in the composition of the tick population among hedgehog populations decays with geographical distances. Azimi Hasani and Hasani (2008) reported infestation of hedgehogs with Rhipicephalus appendiculatus in the suburb of Tabriz city. Since the distribution of this species is limited to African sub Sahara [35], in our view, the authors committed a definite misidentification and therefore the specimens are needed to be carefully re-identified. Hedgehogs are small mammals and are hence likely to harbour the immature stages of most tick species that infest them. However, in a recent study, immature and mature stages of Haemaphysalis inermis and Rhipicephalus turanicus were recovered from the collected specimens in Iran [37].

In this study, the observed cutaneous lesions were quite severe and are compatible with some metabolic or infectious diseases especially burrowing parasites such as Sarcoptes mite (Acaridae, Sarcoptidea) [31] but no mites or other parasitic and mycotic organisms were found in histopathological sections. It seems the collected ectoparasites (fleas and ticks) could not induce these lesions entirely and some predisposing factors such as bad weather and nutritional conditions, $\mathrm{Zn}$ deficiency or concurrent diseases have played important roles $[13,23]$.

\section{Acknowledgments}

We are indebted to the staff of private nature reserves for providing the opportunity and facilities for us to perform this study. We are also most grateful for the financial support received from the Department of Parasitology at the Faculty of Veterinary Science, University of Tabriz, Iran.

\section{REFERENCES}

[1] L.Abbasian. Records of tick (Acarina: Ixodidae) occurring in Iran and their distributional data. Acarologia,Vol 3,546-559,1991.

[2] J.Ashrafihelan, A.Nematollahi, P. Zare, A.Haghi Noshahr, M.Azari, N.Zaboli, M.Norouzi, F. Afi, F.Malekipur, F. Severe pathologic lesions of skin and lung due to heavy parasitic infestation in hedgehogs in Tabriz, Iran. $17^{\text {th }}$ Iranian veterinary congress, 23-24,2012.

[3] F.Azimi Hasani, B.Hasani, B. Survey of Rhipicephalus appendiculatousin hedgehogs in Tabriz, Iran. $15^{\text {th }}$ Iranian veterinary congress, 87-88,2006.

[4] W.Beck, Endoparasites of the hedgehog. Angew, Parasitology, Vol 28,137-41,2007.

[5] P.Botella, J.G.Esteban. Histopathology of the stomach lesion caused by Phyasaloptera brevivaginata (Nematoda, Physalopteridae) in bats in Spain. Folia. Parasitology, Vol 42, 143-148,2005.

[6] V.Y.Cirak, B.Senlik, A.Aydogdu, M.Selver, V.Akyol . Helminth parasites found in hedgehogs (Erinaceus concolor) from Turkey. Preventive Veterinary Medicine, Vol 97,64-69,2010.

[7] S.Fathi. Report of the lungworms (Crenosoma striatum) infestation in Long-eared Hedgehog. $15^{\text {th }}$ Iranian veterinary congress, 231-232,2011.

[8] E.Firouz .Hedgehog. In: The complete fauna of Iran.I.B.Tauris \&Co.Ltd.London, 2005.

[9] G.Gaglio, S.Allen, L.Bowden, M. Bryant, E.R.Morgan. Parasites of European hedgehogs (Erinaceus europaeus) in Britain: epidemiological study and coprological test evaluation. Eur. Journal of Wildlife Researches, Vol 56, 839 844,2010

[10] S.R.Goldberg, C.R.Bursey. Phyasaloptera retusa (Nematoda, Physalopteridae) in naturally infected sagebrush lizards, Sceloporus graciosus (Iguanidae). Journal of Wildlife Disease, Vol 25, 425-429,1989.

[11] H.Golezardy. A survey on the rate of infection of small ruminants with lungworm Mullerius capillaries in the suburb of Tabriz city, Iran. Thesis, 1999. 
[12] S.M.Hoseini, M.R.Youssefi, R.Dozouri, A.Mousapour, S.Ramezanpour, S. Omidzahir, M.T.Rahimi.

Histopathological study of gastric lesions caused by Physaloptera clausa in the hedgehog. Comparative Clinical Pathology, Vol 16,240-245,2012.

[13] E.Isenbugel, R.A.Baumgartner. Diseases of the Hedgehog. In: Zoo and Wild Animal Medicine, Current Therapy 3. Edited by M.E. Fowler, WB Saunders, Philadelphia, 294-302,1993.

[14] M.Khaldia, M.Socolovschib, G.Benyettoua, M.Barecha, T.Bichec, D.Kernifb, P, Raoultb. Rickettsiae in arthropods collected from the North African Hedgehog (Atelerix algirus) and the desert hedgehog (Paraechinus aethiopicus) in Algeria', Comparative Immunology. Microbiology Disease, Vol 35, 117-22,2012.

[15] A.Laux. Extent and intensity of endoparasitic infection in the hedgehog.Angew. parasitology, Vol 28,137-141,1987.

[16] J.McCarthy, T.A.Moore. Emerging helminthes zoonoses.International. J. Parasitology,Vol30,1351-1360,200 0 .

[17] S.K.Majeed, P.A.Morris. J.E.Cooper, J.E. Occurrence of the lungworms Capillaria and Crenosoma spp. in British hedgehogs (Erinaceus europaeus). Comparative Clinical Pathology, Vol 100, 27-36,1989.

[18] H.Mizgaiska-Wiktor, W,Jarosz, B. Piiłacińska, S.Dziemian. Helminths of the hedgehog, Erinaceus europaeus and E. roumanicus from Poznań region, Poland coprological study. Wiadomo. ści .parazytologiczne, Vol 56, 329-32,2010.

[19] Z, Mazlum. Ticks of domestic animals in Iran:Geographic distribution, host relation, and seasonal activity.Journal of Veterinary Faculty University of Tehran, Vol 27,1-32,1971.

[20] S.Nabian, S.Rahbari. Occurrence of soft and hard ticks on ruminants in Zagros mountainous areas of Iran .Iranian Journal of Arthropod-Borne Disease,Vol 2,16-20,2008.

[21] S.Naem, A.A.Farshid, M.Tanhai Marand. Pathologic findings on natural infection with Phyasaloptera praeputialis in cats. Veterinarski Archiv, Vol 76 , 315-321,2006.

[22] A.Nematollahi, M.Azari, N.Zaboli, M.Norouzi, M. A survey on the parasitic fauna of hedgehogs in Tabriz city, Iran. $17^{\text {th }}$ Iranian veterinary congress, 56,2012.

[23] S.Paterson. Skin diseases of exotic pets. $1^{\text {st }}$ edition, Blackwell Science, 2006

[24] L.Polley, E.Hoberg, S.Kutz. Climate change, parasites and shifting boundaries. Acta. Veterinary Scandinavia, Vol 52, $51-55,2010$
[25] G.Poglayen, S.Giannetto, E.Brianti G.Scala, G.Garippa, D.Capelli, N.J.Scaravelli. Helminths found in hedgehogs (Erinaceus europaeus) in three areas of Italy .Veterinary Record,Vol 152, 22-24,2003.

[26] A. Richard, R.A.Heckmann, O.M.Amin, A.Halajian, M.Atif, A.M.El-Naggar. The morphology and histopathology of Nephridiacanthus major(Acanthocephala:Oligacanthorhynchidea)from hedgehog in Iran. Parasitology Research, Vol 6,34-39,2012.

[27] S.Rahbari. Studies on some ecological aspects of tick fauna of West Azarbayjan ,Iran .Journal of Applied Animal Research, Vol 7,189-194,1995.

[28] Gh.Razmi, M.Glinsharifodini, S.Sarvi,S. Prevalence of ixodid ticks on cattle in Mazandaran province, Iran. Korean Journal of Parasitoogyl, Vol 45,307-10,2007.

[29] P.Y.Riley, B.Chomel. Hedgehog Zoonosis. Emerg. Infective Disease, Vol 1, 1-5,2005.

[30] E.J.L.Soulsby, Helminths, protozoa and arthropods in domesticated animals. Bailiere tindall,London,1982.

[31] W.M.Samuel, M.J.Pybus, A.A.Kocan, A.A. Parasitic diseases of Wild mammals. $2^{\text {nd }}$ edition, Manson Publishing. The Veterinary Press, 2001.

[32] L.Sykes, J.Durrant J. The natural hedgehog. Gaia Books, London.2001.

[33] M.Visser, S.Rehbin, C.Wiedemann, C. Species of flea (Siphonaptera) infesting pets and hedgehogs in Germany. Infective Disease, Vol 48,197-202,2001.

[34] A.R.Walker, A.Bouattour, J.L.Camicas, A.Estrada-Peña, I.G.Horak, A.A.Latif, R.G. Pegram, P.M.Preston. Ticks of domestic animals in Africa: a guide to identification of species.Biosciences report, 1-22,2007.

[35] J.B.Walker, J.E.Keirans, I.G.Horak. The genus Rhipicephalus (Acari: Ixodidae): a guide to the brown ticks of the world. Cambridge: Academic Press,2000.

[36] I.Whiting. Prevalence of Endoparasites in the European hedgehog (Erinaceus europaeus)within regions of the East midlands. Reinvention, Vol 15,196-201,2012.

[37] M.R.Yousefi, M.T.Rahimi, M.Hosseini, M.M.Darvishi. First report of Rhipicephalus turanicus from hedgehog (Erinaceus concolor) in north of Iran. World. Journal of Zoology, Vol $6,401-403,2011$.

[38] H.Ziaei. A field guide to the mammals of Iran, Ed. Iran Wildlife Center. 2008

[39] R. N.Nowak.Walker;s mammals of the world.Six ed.The John Hpkins University Press.Baltimore and London.1999. 